\title{
On Editing the International Journal of Primatology
}

\author{
Joanna M. Setchell
}

Published online: 5 February 2012

(C) Springer Science+Business Media, LLC 2012

I took over as editor-in-chief of the International Journal of Primatology in January 2009, when Russell H. Tuttle retired after 20 years of service. After 3 years I feel that I have settled in, and wish to take this opportunity to report on the journal. I presented submission statistics, handling times, etc. at the XXIIIth Congress of the International Primatological Society in Kyoto, Japan, in 2010 (also published in the International Primatological Society bulletin) and will do the same at the XXIVth congress in Cancun this year. Here, I want to concentrate on the state of the journal, acknowledge all the work that goes on behind the scenes, and present plans for the future.

\section{State of the Journal}

The International Journal of Primatology is an official organ of the International Primatological Society. It first appeared in 1980 and remains faithful to the vision of the founding editors Gerald A. Doyle and Matt Cartmill. In addition to being "a carefully reviewed primatological journal of high quality" (Doyle and Cartmill 1980, p. 1) and devoted to fundamental research on primates, it aims to promote the survival of the primate populations of the world. Russ Tuttle continued this vision, encouraging submissions on a broad diversity of topics, with an emphasis on the study of freeranging primates (Tuttle 1989). He also introduced the "Vivamus" logo, which highlights papers on endangered or threatened primate species. I hope to continue this vision and to build on the strong foundations laid by previous editors.

In 2009-2012, we published 238 articles by 710 authors at 425 institutions in 48 countries (data from www.authormapper.com). As reflected in the journal title, we receive submissions from all over the world (Table I; Fig. 1). The top 20 contributing institutions during 2009-2012 are spread across Asia, Europe, Latin America, and the United States (Table II). Of course, these data reflect the country in which authors 
Table I Papers published in 2009-2011 by author affiliations (country)

\begin{tabular}{|c|c|c|c|c|}
\hline Country & 2009 & 2010 & 2011 & Total \\
\hline Argentina & 1 & 2 & 3 & 6 \\
\hline Australia & 2 & 2 & 1 & 5 \\
\hline Austria & & 2 & & 2 \\
\hline Belgium & 1 & 2 & 7 & 10 \\
\hline Bolivia & 1 & 1 & & 2 \\
\hline Brazil & 6 & 5 & 5 & 16 \\
\hline Cameroon & 1 & & & 1 \\
\hline Canada & 4 & 2 & 5 & 11 \\
\hline China & 5 & 3 & 3 & 11 \\
\hline Colombia & & 1 & 1 & 2 \\
\hline Congo, Brazzaville & 1 & & & \\
\hline Congo, Democratic Republic of & & & 1 & 1 \\
\hline Czech Republic & & 1 & & 1 \\
\hline Denmark & & & 1 & \\
\hline Ecuador & & 1 & 1 & 2 \\
\hline Ethiopia & & 1 & & 1 \\
\hline France & 4 & 2 & 9 & 15 \\
\hline Gabon & 2 & 1 & 1 & 4 \\
\hline Germany & 14 & 13 & 21 & 48 \\
\hline India & & & 6 & 6 \\
\hline Indonesia & 2 & 4 & 3 & 9 \\
\hline Ireland & 1 & & & 1 \\
\hline Italy & & 3 & 7 & 10 \\
\hline Ivory Coast & 1 & & & \\
\hline Japan & 6 & 9 & 8 & 23 \\
\hline Kenya & & 1 & 1 & 2 \\
\hline Kuwait & & & 1 & 1 \\
\hline Madagascar & & 2 & 6 & 8 \\
\hline Malaysia & 1 & & 1 & 2 \\
\hline Mexico & 1 & & 4 & 5 \\
\hline Netherlands & & 1 & & 1 \\
\hline New Zealand & 2 & & & 2 \\
\hline Nigeria & 1 & & & 1 \\
\hline Norway & & 1 & & \\
\hline Panama & 1 & & & 1 \\
\hline Peru & 1 & & 2 & 3 \\
\hline Rwanda & & & 1 & 1 \\
\hline Singapore & & 1 & 1 & 2 \\
\hline South Africa & & & 3 & 3 \\
\hline Spain & 3 & 1 & 3 & 7 \\
\hline Sri Lanka & & & 1 & 1 \\
\hline
\end{tabular}


Table I (continued)

\begin{tabular}{lllll}
\hline Country & 2009 & 2010 & 2011 & Total \\
\hline Switzerland & 2 & 1 & 4 & 7 \\
Tanzania & 1 & & 1 & 2 \\
Thailand & 1 & 2 & 4 & 7 \\
Uganda & 1 & 17 & 28 & 46 \\
United Kingdom & 1 & 23 & 41 & 87 \\
United States & 23 & & & 2 \\
Vietnam & 2 & 105 & 185 & 383 \\
Total & 93 & &
\end{tabular}

Note that these data are based on the affiliations for all contributors, unlike previous reports which were based on the affiliation of the corresponding author (Dominy 2004; Tuttle 2008). This is not a comment on the value of the different data sets, but simply due to the relative ease with which I could obtain the data

work, rather than those from which they originate. Examining comparable data for previous years reveals that the relative contributions of Latin America, Asia and Australasia, Africa, and Europe are all increasing and that the international diversity of contributions is improving over time (Fig. 1). This is excellent news, although there is clearly still room for more input from primatologists based in habitat countries.

Assigning papers to topics is difficult, as many fit under more than one category. However, a glance at the tables of content for the past 3 years reveals that conservation and behavior, particularly of wild primates, predominate. Keyword tag clouds for the

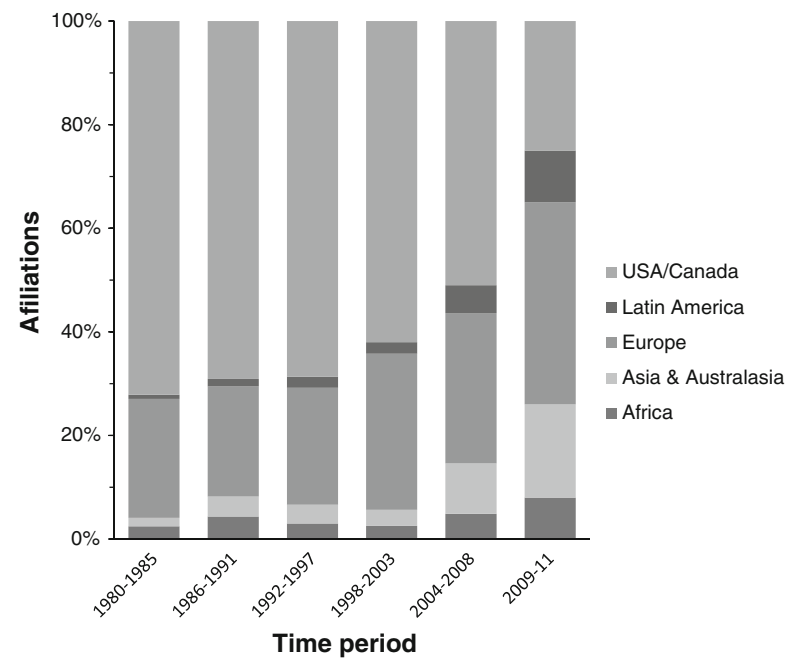

Fig. 1 Papers published in 2009-2011 by geographic region, based on author affiliations. Time periods are those examined in a previous editorial (Dominy 2004), updated with data for 2004-2011. Note that the first four time periods are each 6 years, 2004-2008 is 5 years, and 2009-2011 is only 3 years. Data from www. authormapper.com. Note that these data are based on the affiliations for all contributors, unlike previous reports which were based on the affiliation of the corresponding author (Dominy 2004; Tuttle 2008). This is not a comment on the value of the different datasets, but simply due to the relative ease with which I could obtain the data. 
Table II Top 20 contributing institutions during 2009-2011

\begin{tabular}{lll}
\hline Institution & Country & Number of contributions \\
\hline Kyoto University & Japan & 16 \\
Max Planck Institute for Evolutionary Anthropology & Germany & 14 \\
German Primate Center & Germany & 13 \\
Wildlife Conservation Society & & 11 \\
University of California & USA & 10 \\
University of Cambridge & United Kingdom & 10 \\
University of Stirling & United Kingdom & 8 \\
University of Göttingen & Germany & 7 \\
Chinese Academy of Sciences & China & 5 \\
Free University of Brussels & Belgium & 5 \\
Roehampton University & United Kingdom & 5 \\
University of Zurich & Switzerland & 5 \\
Consiglio Nazionale delle Ricerche & Italy & 4 \\
Osaka University & Japan & 4 \\
Stony Brook University & USA & 4 \\
Texas A\&M University & USA & 4 \\
Universidad Nacional Autónoma de México & Mexico & 4 \\
University of Chicago & USA & 4 \\
CNRS, UMR7178, Strasbourg & France & 3 \\
Dali University & China & 3 \\
\hline
\end{tabular}

Data from www.authormapper.com

journal in www.authormapper.com suggest the same. In terms of taxonomic representation (Fig. 2), tarsiers are well represented, thanks mainly to a special issue devoted to them. Old and New World monkeys are roughly similar in representation,

Fig. 2 Taxonomic representation in papers published in 2009-2011.

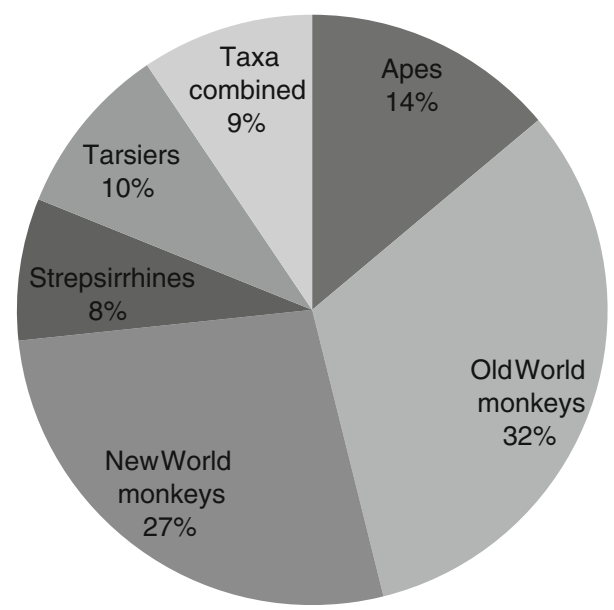


and together with the apes account for $73 \%$ of papers. There is a clear scarcity of manuscripts on strepsirrhines.

In addition to a good flow of regular submissions, we have published four guest-edited special issues since 2009, and have three more in preparation.

Published:

- Primate Coloration: Measurement, Mechanisms and Function, guest-edited by James P. Higham (2009)

- Comparative Functional Morphology in Primates, guest-edited by Yuzuru Hamada, Eishi Hirasaki, and Todd C. Rae (2010)

- Building Bridges Toward a New Understanding of Tarsier Diversity, guest-edited by Myron Shekelle and Sharon Gursky-Doyen (2010)

- Group Coordination and Decision-Making, guest-edited by Cedric Sueur and Andrew King (2011)

In preparation:

- Innovative Methods in Feeding Ecology, guest-edited by Erin Vogel and Janine Chalk

- Multilevel Societies, guest-edited by Cyril Grueter, Ikki Matsuda, Zhang Peng, and Dietmar Zinner

- Social Behavior of Early Hominins, guest-edited by J Michael Plavan

The criteria for publication in a special issue are the same as for a regular submission. Guest editors play the same role as an associate editor for their special issue, handling the review process, assessing manuscript and reviews, and inviting revisions as appropriate, then submitting a final recommendation to me of accept or reject. Special issues are published in print once all the papers are ready. However, to avoid delaying the publication of regular submissions by more than one issue, we don't publish two consecutive special issues.

I update the Instructions for Authors periodically, based on issues that come up during the editorial process. However, it is clear that the authors of many submitted manuscripts do not read them. "Please refer to the Instructions for Authors" is probably the most common phrase in my decision letters! Authors, please bear in mind that a happy editor is more likely to be on your side when making decisions. We have also introduced a requirement for an explicit ethics statement in submitted manuscripts. Finally, we adhere to the Committee on Publication Ethics (COPE) Code of Conduct and Best Practice Guidelines (http://publicationethics.org). I also rely on COPE's guidelines when investigating allegations of publication misconduct.

\section{The Editorial Process and Editor's Acknowledgments}

\section{Associate Editors}

As editor-in-chief, I benefit from the help and advice of several excellent associate editors. Once assigned to a manuscript, the associate editors select and invite reviewers, assess the manuscript and reviews, request and assess revisions as appropriate, and make 
final recommendations of accept or reject to me. I appointed Eduardo Fernandez-Duque, Jessica Rothman, Oliver Schülke, and Charles Snowdon in 2009. Chuck Snowdon retired at the end of 2011. I've been very grateful for his advice, which is based on an enormous amount of editorial experience at Animal Behaviour, Journal of Comparative Psychology, and Behaviour. I am delighted to announce that James Higham joined us as an associate editor in January 2012. James guest-edited a 2009 special issue of the journal, so he knows what to expect. I am particularly grateful to Jess Rothman for her additional help when I'm away from the Internet.

When appointing associate editors I aim to maintain a broad a spread of theoretical expertise, as well as taxonomic and international coverage. I'm aware that we have a taxonomic gap where the strepsirrhines should be (although Oliver's Ph.D. was on fork-marked lemurs), and that we all concentrate on the study of free or semi-free-ranging primates. Moreover, the current associate editors and I are all ecologists or behavioral ecologists. This broadly reflects the manuscripts we get, and therefore the workload, but not the scope of the journal, which includes anthropology, anatomy, ethology, paleontology, psychology, sociology, and zoology.

\section{The Editorial Board}

The editorial board serves to broaden the scope and range of expertise beyond that of the editors. My aim is that the composition of the board should also reflect the international nature of the journal. I am instituting a term of service for editorial board members, which will be renewable after 3 years. However, this is a gradual process, as I have no desire for a sudden turnover. Members of the editorial board contribute actively to the development and good management of the journal, and I am grateful for their advice. They act as ambassadors for the journal, support and promote the journal, seek out the best authors and best work and actively encourage submissions, and review submissions on a more regular basis than other reviewers.

I am grateful to members of the editorial board who have retired since 2009: Irwin S. Bernstein, Frans de Waal, Robin I. M. Dunbar, Jack Fooden, Alex Harcourt, Dario Maestripieri, Leanne Nash, Robert Sussman, Chia Tan, Caroline Tutin, and Carel P. van Schaik. Sadly, another member, Toshisada Nishida, died in 2011 (Mitani et al. 2012). I have appointed the following new members: Agustin Basabose, Diane Brockman, Marie Charpentier, Jöerg Ganzhorn, Thomas Gillespie, Sharon Gursky, Anthony Rylands, and Joan Silk.

\section{Reviewers}

Reviewers' evaluations play a major role in editorial decisions as to whether to accept a manuscript for publication. We use a wide range of sources to identify potential reviewers, including the editorial board, author suggestions, personal knowledge, and bibliographic databases. Conscientious peer review is a time-consuming task but is essential to ensure the quality of the scientific record. The purpose of peer review is to determine the suitability of a manuscript for publication and its contribution to the field, as well as to provide constructive criticism that will improve the final version, even if it does not appear in this journal. This latter point can slip the mind of both reviewer and author on occasion. It is particularly relevant to an international journal, where some 
authors do not have easy access to experts in their field. We have introduced Guidelines for Reviewers on the journal website, which are relevant both for those who are new to reviewing and for established reviewers.

Peer review is also a major bottleneck in manuscript turnaround times, as for other journals (McPeek et al. 2009). Authors are keen to receive constructive comments from experts in their field, but potential reviewers decline invitations. It can take days or even weeks to identify suitable expert reviewers who accept an invitation to review. Similarly, authors are keen to receive a speedy decision, but reviewers can be slow in submitting their review, or even fail to respond further once they've accepted an invitation. During 2009, for example, 43\% of reviews were submitted after the due date, a mean of 16 days late. I appreciate that potential reviewers have many other commitments, but a series of declines can make it difficult to identify a willing reviewer with appropriate expertise, with potential implications for the quality of the reviewing process, and any resulting publication (McPeek et al. 2009). Editors, authors, and reviewers are all members of the same community. In other words, we should follow the golden rule of reviewing: "Review for others as you would have others review for you" (McPeek et al. 2009). If, as an author, you expect expert review and a quick decision, please accept review requests and submit your review by the deadline. If you must decline, then suggestions for alternative potential reviewers are a great help and increase our pool of expert advisors, particularly if these are graduate students and post-docs we may not yet have come across.

Authors, in turn, should revise manuscripts carefully following peer review. Not all comments can be addressed, of course, but all merit careful consideration. Revision is not simply an exercise in rebuttal. Where one reader misunderstands, others may too, so it is worth revising the manuscript to improve clarity. This applies to manuscripts that may eventually be accepted for publication, but also to those that have been rejected by other journals (Hochberg et al. 2009). Reviewers who come across problems (and even typographical errors) that they have commented on previously for another journal are understandably annoyed at their wasted effort. As noted previously, if they refuse to review the manuscript as a result, this can compromise the quality of the final paper if and when it is published, and therefore of the scientific record.

We operate a single-blind review system in which the author does not know the identity of the reviewer (unless reviewers choose to reveal their identity). Early in my tenure as editor-in-chief, we discussed the question of double-blind review, in which reviewers are also blind to the identity of the authors. Reviewer behavior can be influenced by characteristics of the author, in addition to scientific quality. For example, the introduction of double-blind reviewing has improved the representation of female authors in papers published in Behavioral Ecology (Budden et al. 2008), although it is not clear whether this is related to an increase in submissions by female authors, i.e., perceptions of decreased bias, or an increase in acceptance rates for female authors (actual decreases in bias). In primatology, submissions contain many clues to research groups, and even to individual authors. Moreover, double-blind review can lead to incorrect assumptions regarding authorship, which may be more problematic than true knowledge. Single-blind review also makes it easier for potential reviewers to identify conflicts of interest. For the moment, then, we are sticking with single-blind, but we remind reviewers here that they should be fair, and 
should report any conflict of interest. We also allow authors to block reviewers in the case of conflict of interest, but again, we trust authors not to abuse this.

Editorial Manager and Production

At Springer, I am grateful to Dieter Czeschlik, who invited me to become editor of the journal, and to Janet Slobodien, editor for ecology and evolutionary biology, for her guidance. I benefit greatly from the services of the journal editorial assistants, who take care of the technical side of Editorial Manager and send polite reminders whenever a manuscript gets "stuck" in the system. Dennis Galvez is currently the journal editorial assistant, and his predecessors are Kalidass Sundaram, Marco Andal, and Greg Alejandro. Once I accept a manuscript, it goes to Terry Kornak for copyediting and then to production; I am grateful to Terry and to the production editor Manuel Heruela and his predecessor Myrene Grande. Papers are published online as soon as they are ready, and appear in print in the next available issue. This is usually the next issue, unless we have a special issue lined up for publication.

\section{Other Acknowledgments}

I am grateful to Russ Tuttle, both for leaving a good pile of manuscripts ready for publication to ease the editorial transition and for the excellent advice that he passed on in person. I am also grateful to the editors of other journals, whose advice I sought when I first received the invitation to become editor and concerning various issues that have arisen over the past 3 years.

\section{Looking to the Future}

I aim to continue to emphasize international representation in the International Journal of Primatology at all levels. I am keen to broaden the scope of the journal so that it reflects our full remit, publishing high-quality original articles that report fundamental research on primates, including laboratory and field studies from diverse disciplines, including anthropology, anatomy, ethology, paleontology, psychology, sociology, and zoology. I hope to attract authoritative reviews that will inform our readership of the current state of our field and would like the International Journal of Primatology to become the journal of choice for both authors and readers of reviews in primatology. I also encourage authors to submit commentaries that aim to stimulate debate or new research, address controversial topics, provide a new interpretation of published data, correct prevalent misunderstandings, or speculate on the implications of recent findings.

Finally, a 2011 piece in Nature about the top 10 big questions in the social sciences (http://www.nature.com/news/2011/110202/full/470018a.html) got me thinking about the top 10 big questions in primatology. I'm hoping to link this to the IPS 2012 meeting in Cancun, on "Primatology's legacy and future challenges." The idea would be to set the agenda for the future of primatology, and one possibility is that this would lead up to a series of reviews in the journal, each laying out one of the "big 
challenges." As noted previously, this should reflect the broad theoretical interests and international nature of our field.

\section{References}

Budden, A. E., Tregenza, T., Aarssen, L. W., Koricheva, J., Leimu, R., \& Lortie, C. J. (2008). Double-blind review favours increased representation of female authors. Trends in Ecology \& Evolution, 23(1), 4-6.

Dominy, N. J. (2004). Publication and citation trends in the International Journal of Primatology: 19802003. International Journal of Primatology, 25.

Doyle, G. A., \& Cartmill, M. (1980). Introductory statement. International Journal of Primatology, 1, 1-2.

Hochberg, M. E., Chase, J. M., Gotelli, N. J., Hastings, A., \& Naeem, S. (2009). The tragedy of the reviewer commons. Ecology Letters, 12, 2-4.

McPeek, M. A., DeAngelis, D. L., Shaw, R. G., Moore, A. J., Rausher, M. D., Strong, D. R., et al. (2009). The golden rule of reviewing. American Naturalist, 173, E155-E158.

Mitani, J.C., de Waal, F. B.M., Hosaka, K., McGrew, W. C., Nakamura, M., Nishimura, A. Wrangham, R. W. \& Yamigiwa, J. (2012). Obituary: Toshisada Nishida. International Journal of Primatology in press.

Tuttle, R. H. (1989). Inaugural editorial. International Journal of Primatology, 10, 267-268.

Tuttle, R. H. (2008). Report on the International Journal of Primatology 2003-2008. International Journal of Primatology, 29, 1391-1393. 